\title{
Estudo comparativo entre técnicas de superposições cefalométricas totais
} Ricardo Fernando Zampieri*, José Fernando Castanha Henriques**, Marcos Roberto de Freitas
Guilherme R. P. Janson

\section{Resumo}

Objetivos: o presente trabalho propôs-se a verificar se existem diferenças entre os resultados propiciados por métodos de superposições totais. Metodologia: utilizou-se uma amostra de 50 telerradiografias de pacientes entre as idades de 8,25 a 16,25 anos, avaliando-se as alterações provenientes do crescimento e desenvolvimento craniofacial e do tratamento ortodôntico, por meio de variáveis cefalométricas representativas da direção e da magnitude dos deslocamentos dos componentes faciais esqueléticos. Resultados e Conclusões: constatou-se que as técnicas de superposições podem produzir informações significantemente diferentes.

Palavras-chave: Superposição cefalométrica. Cefalometria radiográfica. Filmes seriados.

\section{INTRODUÇÃO}

O avanço tecnológico da Ortodontia e Ortopedia Facial relacionado ao advento da cefalometria radiográfica, a partir da técnica publicada por Broadbent ${ }^{8}$, em 1931, não se restringiu apenas à elaboração de diagnósticos e planejamentos ortodônticos mais adequados, mas também habilitou pesquisadores a conduzirem estudos longitudinais mais precisos sobre as alterações espaciais ocorridas nas estruturas da face em função do crescimento e desenvolvimento, o que favoreceu o refinamento de nosso conhecimento acerca deste tema. A cefalometria propiciou a análise padronizada de estruturas que eram anteriormente manipuladas apenas em crânios secos, tornando o estudo do crescimento algo dinâmico, sendo isto possivel, em parte, pela aplicação de vários métodos de superposições de cefalogramas ou de telerradiografias em série obtidas em épocas diferentes. Várias estruturas anatômicas, pontos cefalométricos, linhas e planos de referência foram então utilizados para este propósito, possibilitando inclusive prover uma análise qualitativa dos efeitos do tratamento ortodôntico, o que antes era realizado

* Professor do Curso de Especialização em Ortodontia e Ortopedia Facial - UNOPAR. Aluno do Curso de Mestrado Interinstitucional da Universidade de São Paulo - USP - Bauru e Universidade Estadual de Londrina - UEL.

** Prefeito Administrativo do Campus USP de Bauru. Coordenador do Curso de Pós-Graduação em Ortodontia - Doutorado.

*** Chefe do Departamento de Odontopediatria, Ortodontia e Saúde Coletiva. Coordenador do Curso de Especialização Ortodontia - USP.

**** Coordenador do Curso de Pós-Graduação em Ortodontia - Mestrado. 
somente por meio de modelos de gesso ou de radiografias não padronizadas $2,4,5,6,7,8,9,10,13,14,15,16,17,19$, $20,21,22,23,24,27,28,29,31,33,34,35,37,38,40,42,45,48,50,51$.

\section{REVISÃO DE LITERATURA}

Em seu artigo publicado em abril de 1931, no qual descreve uma técnica radiográfica padronizada que possibilita determinar com precisão as alterações provenientes de crescimento e desenvolvimento ou de tratamento ortodôntico, Broadbent $^{8}$ relatou que os traçados cefalométricos subseqüentes de uma mesma pessoa podem ser superpostos em áreas da base do crânio que não se modifiquem entre certas idades, constituindo uma referência estável a partir da qual podem ser realizadas medições exatas das mudanças nos dentes, maxilares e face. Mencionou que, naquela época, empregavam-se as superposições sobre os Planos de Frankfurt, coincidindo-se os pontos pório, sendo este o método mais freqüentemente utilizado, ou sobre as linhas sela-násio, coincidindo-se os pontos sela e násio quando a distância entre eles não se alterava.

Seis anos mais tarde, Broadbent ${ }^{9}$ mencionou a estabilidade do plano de orientação Bolton-násio e seu ponto de registro $\mathrm{R}$, situado na metade da distância de uma perpendicular do plano Bolton-násio até o centro da sela túrcica, na área esfenoidal, e considerado o ponto mais fixo da cabeça ou da face. De acordo com a técnica, os cefalogramas são superpostos sobre os pontos de registro $\mathrm{R}$, com os Planos Bolton-násio paralelos.

Por meio da cefalometria radiográfica é possível analisar as mudanças que ocorrem durante e após o tratamento ortodôntico, discernindo-se estas alterações por comparação visual entre as telerradiografias ou, mais vantajosa e detalhadamente, por superposições cefalométricas. Para que os cefalogramas sejam corretamente superpostos, Higley ${ }^{20}$ afirmou ser necessário escolher algum método de orientação que se baseie em pontos localizados em áreas sem crescimento, indicando a base do crânio como referência para as superposições.
Segundo relato de De Coster ${ }^{14}$, os estudos cefalométricos de crescimento requerem a determinação de pontos realmente fixos, facilmente visualizados sobre o filme e que apresentem exatidão suficiente que os tornem naturalmente valiosos para medições, comparações ou superposições. Comparando 6 telerradiografias de 3 pessoas, 2 do gênero masculino e 1 do feminino, sendo que as exposições radiográficas iniciais e finais foram conduzidas aos 7 e 23 anos, aos 8 e 21 anos e aos 7 e 18 anos de idade, descobriu que a linha sela túrcica-etmóide-frontal foi absolutamente idêntica e superposta nos 6 filmes, parecendo ser inalterável após os 7 anos. Desta maneira, poderia ser utilizada como um ponto de referência confiável para medições em um mesmo indivíduo durante o crescimento e tratamento ortodôntico.

No intento de se compararem as variações na forma da estrutura óssea facial durante o desenvolvimento, o objetivo primário é a escolha de uma linha de referência convenientemente situada o mais distante possível das regiões de crescimento do crânio ${ }^{5}$.

Para se demonstrarem as alterações ocorridas na face em função do tratamento ortodôntico, torna-se necessária a superposição cuidadosa dos vários traçados cefalométricos e, segundo Steiner ${ }^{45}$, a utilização de linhas contínuas, tracejadas e pontilhadas, que caracterizam as diferentes fases do tratamento, confunde a interpretação das superposições. Deste modo, sugeriu um método simples que emprega cores específicas para cada cefalograma, facilitando sua distinção quando superpostos. Considerando-se o contraste, a sensibilidade fotográfica e a qualidade dos lápis, selecionou as seguintes cores: preta, para o cefalograma inicial; azul, para os intermediários; vermelha, para o final; verde, para os de contenção; marrom, para os subseqüentes. Para identificar sua origem, todas as linhas e figuras são copiadas de um cefalograma aos subseqüentes na sua cor original.

Enlow ${ }^{16}$ explicou que por meio do registro dos cefalogramas sobre pontos de referência relati- 
vamente fixos como, por exemplo, a sela túrcica, torna-se possível demonstrar os movimentos de crescimento aparentes das várias partes da face em relação à base do crânio, visualizando-se as alterações topográficas no aspecto total da face. Isto pode levar a interpretações incorretas, entretanto, ao se denotarem certas direções de crescimento em muitas áreas quando, na verdade, o crescimento local se processa em uma direção completamente diferente, sendo que esta situação se baseia no fato de as técnicas padrão de superposições de traçados cefalométricos utilizarem pontos de referência localizados em ossos separados e não relacionados, cada um crescendo independentemente do outro e em direções, proporções e épocas totalmente diferentes. Não existe um ponto de referência estável ou fixo que possibilite a superposição precisa dos cefalogramas durante o crescimento, pois todas as partes de todos os ossos são submetidas a maiores ou menores quantidades de movimentos de remodelamento. As estruturas ou regiões relativamente estáveis constituem referências úteis na avaliação dos movimentos de crescimento cumulativos entre os diferentes ossos, sendo que nenhum ponto arbitrário pode ser usado para avaliar as mudanças de remodelamento reais entre ossos separados ou entre diferentes partes de um mesmo osso.

A avaliação do crescimento da face pode ser baseada por meio de superposições de telerradiografias, obtidas em estágios diferentes do desenvolvimento, considerando-se, segundo $\mathrm{Björk}^{6}$, a coincidência mais próxima de um número máximo de estruturas da base craniana anterior.

Para comparar telerradiografias obtidas em duas ou mais ocasiões diferentes, Baumrind, Miller e Molthen ${ }^{2}$ explicaram que isto pode ser feito pelo método individual ou por superposições. No método individual, as telerradiografias são primeiramente analisadas por medições em todos os cefalogramas e, em seguida, comparam-se as diferenças entre estas medidas. Através das superposições, o deslocamento relativo das estruturas é avaliado colocando-se os cefalogramas um sobre o outro, com registro em algum "plano" anatômico próximo à estrutura a ser medida, possibilitandose identificar mais precisamente as áreas nas quais as mudanças estão efetivamente ocorrendo. Além disso, as comparações por meio das superposições são geralmente mais sensíveis para estudar pequenos deslocamentos do que o método individual.

Séries de cefalogramas superpostos proporcionam uma representação ilustrada das modificações devidas ao crescimento e tratamento, sendo isto freqüentemente mais valioso do que análises radiográficas individuais. Entretanto, Fischer ${ }^{17}$ relatou que o problema inerente à superposição é a localização de um ponto de referência destituído de mudanças de posição e forma durante todos os estágios de crescimento.

As melhores referências para superposições não se constituem em pontos, mas em áreas de registro naturais. Por outro lado, segundo menção de Mathews e Payne ${ }^{30}$, na ausência de crescimento ou quando o tempo de observação entre as telerradiografias não é grande, os registros habituais de superposições podem ser utilizados. Todavia, estes não são confiáveis para uso durante o surto de crescimento da adolescência, quando o ortodontista não possui controle ou conhecimento acerca da velocidade e duração do crescimento. Recomendaram prudência quando se empregam pontos de referência naturais para superposições durante um período extenso de crescimento.

Em uma revisão sobre cefalometria radiográfica, Ricketts ${ }^{41}$ relatou que o ponto sela tornou-se popular devido à facilidade em sua identificação preferencialmente a seu mérito científico ou confiabilidade anatômica.

Em estudos de crescimento longitudinais, os pontos sela e násio devem ser ajustados devido aos deslocamentos por crescimento a que estão sujeitos. Deste modo, Björk e Skieller ${ }^{7}$ propuseram um método que transfere a linha sela-násio da primeira radiografia às subseqüentes, após superposição sobre certas estruturas da base craniana anterior e abóbada craniana. 
Objetivando investigar se um maior intervalo de tempo entre as telerradiografias relaciona-se com uma menor precisão das superposições dos cefalogramas, devido a mudanças de crescimento e remodelamento das áreas de referência da base do crânio, McWilliam ${ }^{32}$ utilizou uma amostra de telerradiografias de 22 pessoas do gênero feminino, sendo que os filmes foram obtidos anualmente dos 9 aos 16 anos de idade, e o período de observação variou de 1 a 7 anos. Efetuaram-se as superposições dos cefalogramas seriados subseqüentes sobre a área da base do crânio, examinando-se os erros médios rotacionais e translacionais das localizações dos limites envolvidos. Observou apenas uma suave tendência de diminuição da exatidão das superposições em intervalos maiores de tempo, entretanto, houve uma súbita queda de precisão entre 11 e 12 anos de idade, época que coincide aproximadamente com o surto de crescimento pubescente, quando as atividades de remodelamento poderiam influenciar a região da base craniana. Assim, as análises que não cobrem o período de crescimento pubescente podem ser vantajosas, mesmo em intervalos maiores de observação. Concluiu que se pode obter uma maior confiabilidade das superposições por eliminação dos procedimentos do desenho anatômico, registrandose os limites diretamente sobre as radiografias.

Esclarecendo alguns pontos importantes acerca das superposições cefalométricas, Houston e Lee $^{22}$ explicaram que a superposição direta das telerradiografias é simples, rápida e não requer materiais específicos, com seu nível de reprodutibilidade comparando-se favoravelmente a outros métodos e, quando as radiografias seriadas são digitalizadas, sua superposição direta torna-se, obviamente, o procedimento de escolha. Contudo, a reprodutibilidade da superposição dos cefalogramas também é satisfatória, desde que estes sejam confeccionados com grande cuidado, delimitandose consistentemente, com material apropriado, as superfícies das placas corticais ósseas. A confiabilidade de qualquer método de superposição depen- derá de muitos fatores, incluindo-se a qualidade das radiografias originais, a cautela e experiência do operador e o protocolo utilizado no registro da superposição. Averiguando a exatidão de diferentes métodos de superposições sobre estruturas da base do crânio, relataram que para se estudarem as modificações ocorridas em função de crescimento ou tratamento, os registros radiográficos deveriam ser superpostos em estruturas estáveis durante o intervalo de tempo em questão.

$\mathrm{Na}$ análise de registros cefalométricos seriados, Macri e Athanasiou ${ }^{29}$ recomendaram que todos os cefalogramas de um mesmo paciente sejam desenhados em uma mesma ocasião. Em relação às fontes de erro relacionadas a métodos de superposições, alertaram que qualquer variação devida a processos de remodelamento das estruturas de referência pode alterar o resultado da superposição e conduzir a conclusões errôneas sobre os vetores de crescimento. Entretanto, torna-se importante selecionar estruturas sujeitas a pequenas mudanças de remodelamento, com vistas a assegurar a validade do método. A reprodutibilidade das estruturas anatômicas de referência é outra fonte de erro em superposições cefalométricas.

Antes de delimitar o desenho da telerradiografia cefalométrica torna-se necessário reconhecer a anatomia da cabeça, em particular os componentes ósseos do crânio e da face. Caufield ${ }^{12}$ sugeriu que qualquer livro disponível a este respeito deva ser consultado, bem como o acesso a um crânio seco é também proveitoso, pelo menos inicialmente, como um auxílio na identificação de vários limites ósseos. Para certas aplicações tais como estudos seriados ou pós-tratamento, torna-se útil desenhar todos os limites anatômicos possíveis na área da base do crânio, no palato e na mandíbula (incluindo o canal mandibular quando visível), proporcionando-se uma melhor base para superposições de radiografias seriadas. Os detalhes observados no desenho das estruturas internas do crânio são úteis na orientação dos cefalogramas longitudinais ou seriados, visando-se avaliar mudanças de cresci- 
mento e efeitos do tratamento ortodôntico, pois o crânio experimenta pouca alteração após a criança atingir 7 anos de idade.

Sobre as limitações dos métodos tradicionais de superposições, Jacobson ${ }^{23}$ afirmou que, em adição aos erros de distorção e identificação de limites, existe um grupo adicional de erros associado especificamente com a inexatidão durante o ato de superpor os traçados cefalométricos e, deste modo, quando erros rotacionais e translacionais são introduzidos, cada ponto do cefalograma mais recente é deslocado de sua posição "verdadeira" de um modo matematicamente preciso. Erros em superposições de cefalogramas podem ser também oriundos da técnica de superposição utilizada para a interpretação dos resultados. O comportamento do crescimento de uma pessoa, registrado em telerradiografias seqüenciais, difere grandemente quando estudado por métodos diferentes de superposições. Ao passo que uma técnica de superposição possa exibir o comportamento de crescimento mais corretamente do que outra, não há um modo matemático objetivo que determine ser um método de superposição em particular superior a outro.

A cefalometria radiográfica seriada é utiliza$\mathrm{da}$, quase desde o princípio de seu advento, para medir mudanças de crescimento craniofacial e tratamento. Não obstante os debates sobre os méritos de vários métodos de estudo do crescimento, Jacobson e Sadowsky ${ }^{24}$ enfatizaram a necessidade de avaliação da quantidade de mudança dentofacial, com razoável exatidão, entre dois filmes obtidos em épocas distintas. Apesar de as superposições de traçados cefalométricos não serem completamente exatas, em função da ausência de linhas de referência ou limites anatômicos estáveis, relataram que, mesmo assim, elas servem para o propósito valioso de avaliação geral das alterações resultantes de crescimento e/ou tratamento ortodôntico.

A estabilidade da base do crânio utilizada por De Coster $^{14}$ no emprego das superposições de radiografias cefalométricas, segundo relato de Moorrees, Efstratiadis e Kent Junior ${ }^{35}$, revelou outras características e padrões estáveis de linhas opacas na imagem radiográfica da base craniana em cada telerradiografia. Estes padrões intensificam a confiabilidade da superposição na base do crânio para estudos de crescimento e análises dos resultados do tratamento. Eles correspondem às arestas corticais opacas medial e superior dos tetos das órbitas, camadas corticais internas do osso frontal, asas menores do esfenóide, marcações tênues no contorno superior do etmóide, córtex do plano esfenoidal, margem ventral do seio esfenoidal, superfícies corticais internas (cerebrais) ventral e caudal da sela túrcica e os contornos do clivo (base posterior do crânio). O contorno completo da sela túrcica não é sempre confiável, visto que a parte dorsal remodela-se à medida que a glândula pituitária cresce. Esta bateria de áreas anatômicas prontamente identificáveis facilita a superposição rápida e reproduzivel dos cefalogramas.

Em um estudo cefalométrico acerca de superposições, Baumrind et al. ${ }^{3}$ relataram que a identificação de estruturas relativamente estáveis não é simples, visto que quase todos os ossos do complexo craniofacial são submetidos a modificações contínuas durante o desenvolvimento. Mesmo onde a forma dos ossos parece permanecer relativamente constante com o passar do tempo, o crescimento ocorre não por expansão proporcional em todas as direções, mas como resultado de reabsorções sobre algumas superfícies ósseas e aposições sobre outras.

Técnicas de superposições cefalométricas totais têm o objetivo comum de prover informações acerca das modificações ocorridas em decorrência do crescimento e desenvolvimento e do tratamento ortodôntico, podendo, entretanto, produzir resultados diferentes de acordo com as áreas de referência preconizadas em cada método de superposição. Assim, torna-se interessante analisar se as diferenças encontradas podem ou não conduzir a interpretações significantemente diferentes. 


\section{PROPOSIÇÃO}

Propõe-se verificar se existem diferenças relativas à direção e magnitude dos deslocamentos dentários e esqueléticos demonstrados ao se empregarem as técnicas de superposições cefalométricas totais:

- Estrutural de Björk, Skieller,

- Sobre as linhas sela-násio, coincidindo-se os pontos sela,

- Sobre os pontos de registro $\mathrm{R}$, com os planos Bolton-násio paralelos.

\section{MATERIAL E MÉTODOS Material}

A amostra consistiu de telerradiografias cefalométricas em norma lateral obtidas antes e após o tratamento ortodôntico de 25 pacientes, sendo 11 do gênero masculino e 14 do feminino, com idade média de 11,37 anos ao início da terapia ortodôntica, variando de 8,25 a 16,25 anos. Dez pacientes apresentavam más oclusões de Classe I e 15 de Classe II, divisão 1, e foram tratados com aparelhos "Edgewise" convencionais e extrações de quatro pré-molares. O tempo médio decorrido entre as exposições radiográficas iniciais e finais foi de 5,27 anos, variando de 2,25 a 9,5 anos.

\section{Métodos}

Para a obtenção das telerradiografias cefalométricas laterais pré e pós-tratamento foram obedecidos os critérios de padronização convencionalmente aceitos para a exposição radiográfica e o processamento dos filmes, sendo que os pacientes da amostra foram orientados a permanecerem com os lábios em repouso e em posição de máxima intercuspidação habitual. $\mathrm{O}$ posicionamento da cabeça, com o lado esquerdo da face voltado para o filme, foi orientado por um cefalostato tipo Margolis que mantinha uma distância de 1,52 metro do ponto focal do aparelho de raios- $\mathrm{X}$ ao plano médio sagital, produzindo-se um fator de magnificação da imagem radiográfica constante de $8,95 \%$, em relação ao tamanho real das estrutu- ras do complexo craniofacial, tornando possíveis as superposições seqüenciais dos filmes e traçados cefalométricos. O chassi, contendo filme 18 x 24 centímetros e ecrans intensificadores, era acoplado ao cefalostato com um filtro de alumínio chanfrado justaposto em sua superfície externa para se melhorar o contraste dos tecidos moles do perfil facial.

Para a elaboração dos cefalogramas empregaram-se: negatoscópio com superfície de trabalho emoldurada para o tamanho do filme com papel cartolina cor preta; 50 telerradiografias cefalométricas laterais; 50 folhas de papel de acetato "ultraphan" com 18 x 24 centímetros e espessura de 0,07 milímetro; fita adesiva fosca; lapiseira Pentel P 205; grafites cores preta e vermelha com diâmetro de 0,5 milímetro; "Tracing Template" Unitek/3M; borracha branca macia. Sobre cada telerradiografia fixou-se uma folha de papel de acetato com fita adesiva fosca em suas extremidades superiores e na metade da margem esquerda. Com o auxílio do negatoscópio procedeu-se ao traçado dos cefalogramas em um ambiente escurecido, controlando-se a intensidade de luz com pedaços de papel cartolina cor preta, com a finalidade de diminuir o esforço ocular e aumentar a visualização das estruturas anatômicas pouco contrastadas. Utilizou-se de concentração e muito cuidado durante a confecção dos cefalogramas, exercendo-se pressão suave e uniforme da grafite sobre o papel de acetato e delimitando-se o desenho anatômico com exatidão, sem interromper os contornos das imagens. Efetuaram-se os cefalogramas de cada par de telerradiografias de um mesmo paciente em seqüência, sendo o inicial confeccionado na cor preta e o final na verme1ha. Cada traçado cefalométrico foi identificado na parte inferior esquerda do papel de acetato, constando-se nome do paciente, número de registro, Classificação de Angle, data da exposição radiográfica e idade em anos, sendo que o desenho anatômico compreendeu o contorno das estruturas relacionadas a seguir (Fig. 1). 
1) margem inferior do forame magno,

2) margem posterior do côndilo do osso occipital,

3) margem inferior do côndilo do osso occipital,

4) margem anterior do côndilo do osso occipital,

5) base do osso occipital,

6) conduto auditivo externo,

7) dorso da sela túrcica,

8) soalho da sela túrcica,

9) tubérculo da sela túrcica,

10) processo clinóide anterior,

11) face superior do corpo do osso esfenóide,

12) margem anterior da grande asa do osso esfenóide,

13) porção horizontal da cortical interna do osso frontal,

14) porção vertical da cortical interna do osso frontal,

15) abóbada da órbita,

16) lâmina crivosa do osso etmóide,

17) cortical externa do osso frontal,

18) sutura frontonasal,

19) osso próprio do nariz,

20) face mais ântero-superior das fossas nasais ósseas,

21) rebordo orbitário externo,

22) soalho da órbita,

23) parede anterior da fossa temporal,

24) parede anterior da apófise piramidal do maxilar,

25) fissura pterigomaxilar,

26) soalho das fossas nasais,

27) margem anterior do palato duro,

28) abóbada palatina,

29) incisivo central superior permanente,

30) primeiro molar superior permanente,

31) cortical interna da sinfise mandibular,

32) cortical externa da sínfise mandibular,

33) borda inferior mandibular,

34) borda posterior mandibular,

35) côndilo mandibular,
36) canal mandibular,

37) incisivo central inferior permanente,

38) primeiro molar inferior permanente,

39) germe do terceiro molar inferior,

40) tecidos moles do perfil facial.

Para o desenho das estruturas anatômicas bilaterais, quando projetavam imagens duplas no filme radiográfico, considerou-se o contorno médio

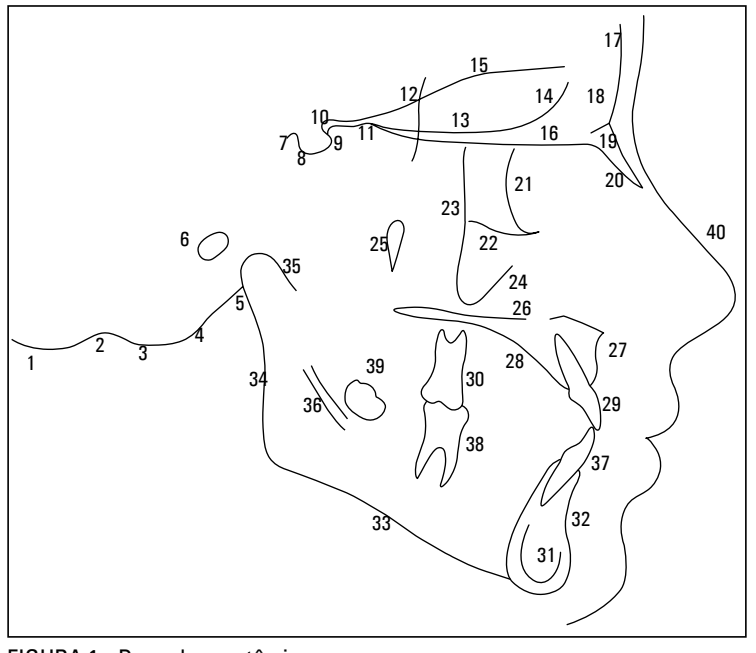

FIGURA 1 - Desenho anatômico.

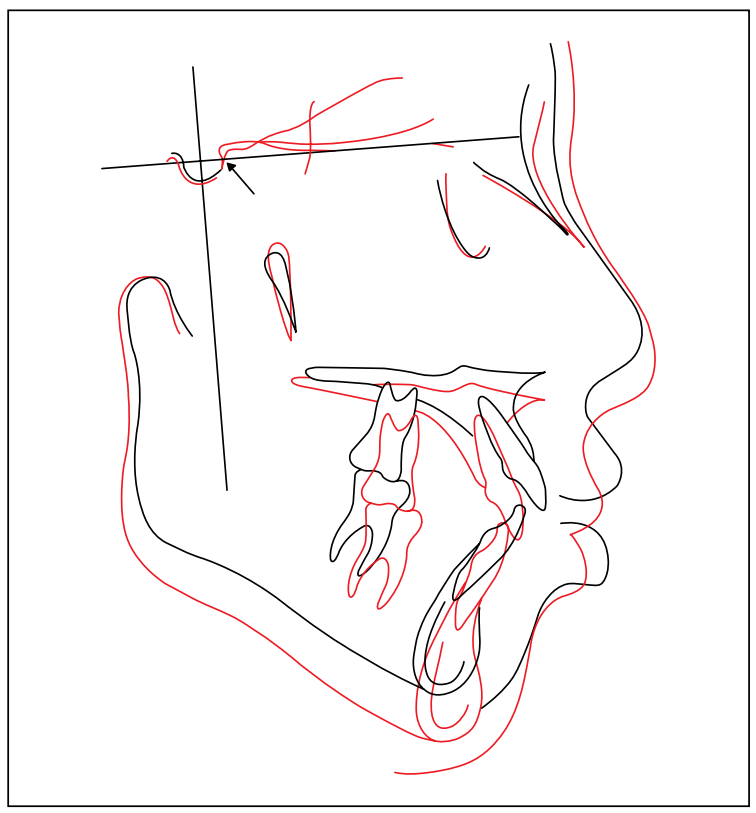

FIGURA 2 - Superposição estrutural de Björk; Skieller (TE). A seta indica 0 ponto de intersecção médio entre os contornos inferiores dos processos clinóides anteriores e o contorno do tubérculo da sela túrcica. 
entre os lados direito e esquerdo para se obter um desenho sagital mediano livre de distorção.

A seguir, demarcaram-se os pontos cefalométricos Bolton, pório, sela, násio, orbitário, $\mathrm{A}$ e pogônio, bem como foram desenhados os planos

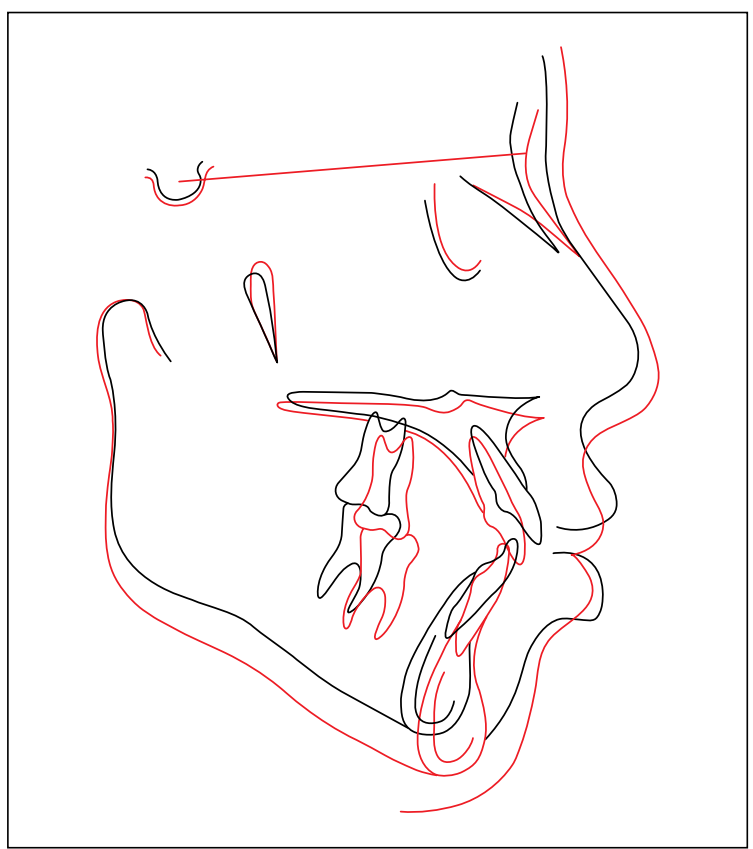

FIGURA 3 - Superposição sobre as linhas sela-násio, coincidindo-se os pontos sela (TSN).

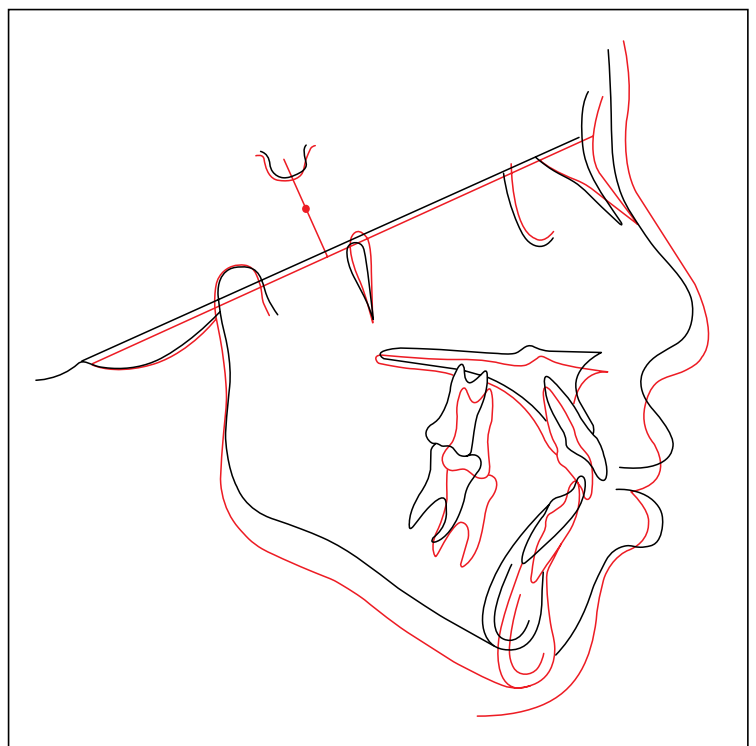

FIGURA 4 - Superposição sobre os pontos de registro $\mathrm{R}$, com os Planos Bolton-násio paralelos (TR).
Bolton-násio e horizontal de Frankfurt e a linha sela-násio, sendo então efetuadas as seguintes técnicas de superposições cefalométricas totais:

1) Superposição estrutural de Björk e Skieller (TE) (Fig. 2)

a) Diretamente sobre a telerradiografia inicial marcaram-se, com lapiseira contendo grafite cor preta de diâmetro 0,5 milímetro, os pontos sela, násio e o ponto de interseção médio entre os contornos inferiores dos processos clinóides anteriores e o contorno do tubérculo da sela. A seguir, desenhou-se a linha sela-násio e uma linha perpendicular passando pelo ponto sela.

b) Diretamente sobre a telerradiografia final, marcou-se o ponto de intersecção médio entre os contornos inferiores dos processos clinóides anteriores e o contorno do tubérculo da sela.

c) Superpôs-se a telerradiografia final sobre a inicial coincidindo-se as seguintes estruturas de referência: no sentido ântero-posterior, o tubérculo da sela túrcica e a margem anterior da grande asa do osso esfenóide e, no supero-inferior, o ponto de interseção médio entre os contornos inferiores dos processos clinóides anteriores e o contorno do tubérculo da sela, a porção horizontal da cortical interna do osso frontal, a lâmina crivosa do osso etmóide e a abóbada da órbita.

d) Diretamente sobre a telerradiografia final, superposta sobre a inicial conforme o item anterior, copiaram-se os desenhos das linhas sela-násio e perpendicular passando pelo ponto sela da telerradiografia inicial.

e) Procedeu-se à elaboração dos cefalogramas inicial e final, acrescentando-se os desenhos das linhas sela-násio e perpendicular passando pelo ponto sela.

f) Superpôs-se o cefalograma final sobre o inicial coincidindo-se os desenhos das linhas sela-násio e perpendicular passando pelo ponto sela.

2) Superposição sobre as linhas sela-násio, coincidindo-se os pontos sela (TSN) (Fig. 3)

a) Desenhou-se a linha sela-násio nos cefalogramas inicial e final. 


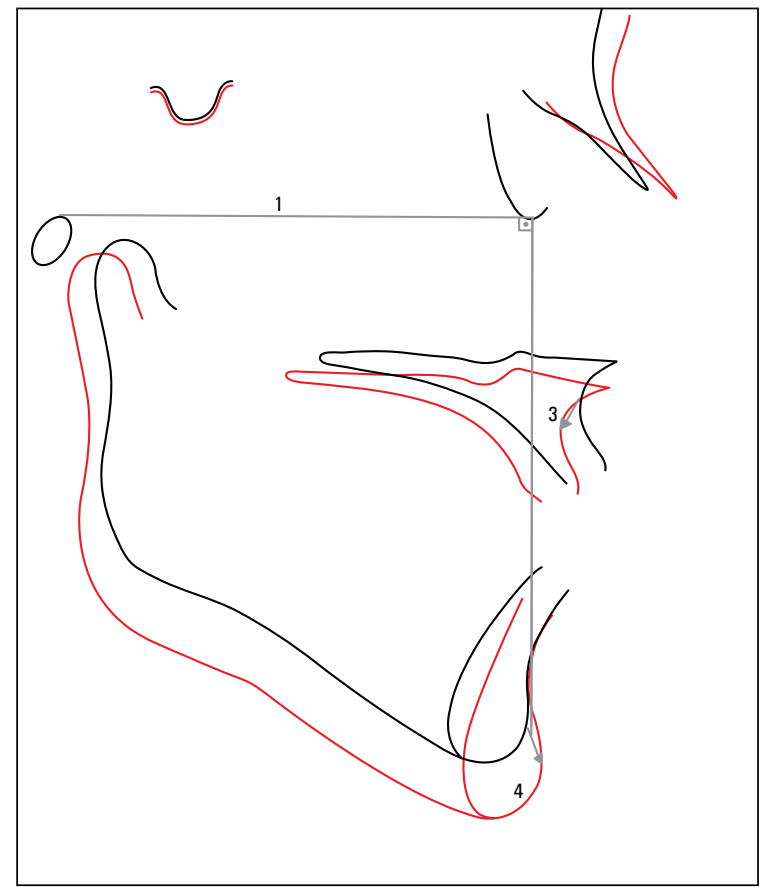

FIGURA 5 - Referências horizontal e vertical e vetores de deslocamento: 1) Referência horizontal (Plano de Frankfurt do traçado cefalométrico inicial). 2) Referência vertical (linha perpendicular à referência horizontal passando pelo ponto orbitário). 3) Vetor de deslocamento da maxila.

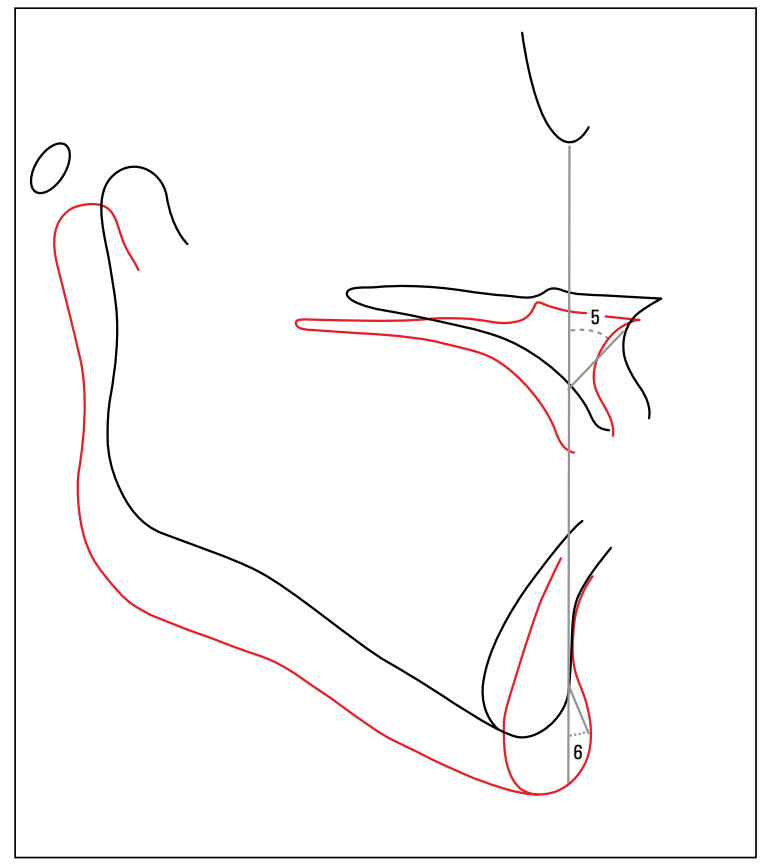

FIGURA 6 - Medidas angulares que traduzem a direção dos deslocamentos da maxila e da mandíbula: 5) Ângulo $a m x$, formado entre o vetor de deslocamento da maxila e a referência vertical. 6) Ângulo amd, formado entre o vetor de deslocamento da mandíbula e a referência vertical. b) Superpôs-se a linha sela-násio do cefalograma final sobre a do inicial, coincidindo-se os pontos sela.

3) Superposição sobre os pontos de registro $R$, com os Planos Bolton-násio paralelos (TR) (Fig. 4)

a) Desenhou-se o Plano Bolton-násio nos cefalogramas inicial e final.

b) Desenhou-se uma linha perpendicular ao Plano Bolton-násio, passando pelo ponto sela, nos cefalogramas inicial e final.

c) Marcou-se o ponto de registro $R$, na metade do comprimento desta linha, nos cefalogramas inicial e final.

d) Superpôs-se o ponto de registro $\mathrm{R}$ do cefalograma final sobre o do inicial, mantendo-se os Planos Bolton-násio paralelos.

Para avaliar a direção e a magnitude dos movimentos dos componentes esqueléticos maxilares e mandibulares, propiciados por crescimento e tratamento ortodôntico e demonstrados pelas técnicas de superposições cefalométricas totais descritas, utilizou-se um sistema coordenado de referência baseado no Plano de Frankfurt do cefalograma inicial e foram realizadas medições angulares e lineares, utilizando-se "cephalometric protractor" (Unitek/3M) e paquímetro, dos deslocamentos da maxila e da mandíbula por meio dos seguintes métodos:

a) O Plano de Frankfurt do traçado cefalométrico pré-tratamento (referência horizontal) foi mantido coincidente à linha horizontal de uma folha de papel milimetrado, sendo desenhada uma linha de referência vertical, passando pelo ponto orbitário, perpendicular àquela referência (Fig. 5).

b) Os movimentos da maxila e da mandíbula, representados pelos pontos cefalométricos $\mathrm{A}$ e Pog, respectivamente, e demonstrados em cada método de superposição total dos cefalogramas pré e pós-tratamento, definiram vetores de deslocamento (Fig. 5).

c) As seguintes medições foram efetuadas (Fig. 6, 7):

- Ângulo amx, formado entre o vetor de deslo- 
camento da maxila e a linha de referência vertical, representando a direção do deslocamento ocorrido na maxila, tanto no sentido anterior (sinal positivo) como no posterior (sinal negativo).

- Ângulo amd, formado entre o vetor de deslocamento da mandíbula e a linha de referência vertical, representando a direção do deslocamento ocorrido na mandíbula, tanto no sentido anterior (sinal positivo) como no posterior (sinal negativo).

- Componentes horizontais (x) e verticais (y) dos vetores de deslocamento, paralelos e perpendiculares, respectivamente, à referência horizontal, representando a magnitude dos movimentos horizontais e verticais ocorridos na maxila e na mandíbula, tanto nos sentidos anterior e inferior (sinal positivo) como posterior e superior (sinal negativo).

A análise estatística descritiva envolveu o uso de tabelas, gráficos e parâmetros de média e desvio-padrão para cada variável cefalométrica. Após a obtenção destes dados, para a realização da estatística indutiva, aplicou-se a análise de variância a um critério (ANOVA) com vistas a comparar as médias dos valores de cada variável dependente estudada. Na observação de um resultado estatisticamente significante, indicativo de desigualdade entre as superposições, utilizou-se o teste de Tukey para comparações múltiplas, com a finalidade de indicar, especificamente, entre quais técnicas estariam ocorrendo as diferenças. Em todas as induções estatísticas foi adotado nível de significância de $5 \%$ para rejeição da hipótese de nulidade.

\section{DISCUSSÃO}

A execução e interpretação corretas de protocolos de superposições cefalométricas possibilitam a análise das alterações decorrentes do crescimento e desenvolvimento e do tratamento ortodôntico sobre os componentes faciais dentários e esqueléticos. Na opinião de Proffit e Fields Junior ${ }^{38}$, torna-se praticamente impossível saber o que está realmente ocorrendo durante o tratamento de um paciente em crescimento sem recorrer às super- posições cefalométricas. Entretanto, diversos fatores influenciam a confiabilidade e os resultados das superposições de radiografias cefalométricas seqüenciais. Com base nas opiniões dos autores pesquisados na literatura, poder-se-ia citar a falta de padronização da técnica radiográfica ${ }^{22,24,25,29}$, a magnificação ${ }^{29}$, a distorção ${ }^{23,29}$, os erros durante a confecção do traçado cefalométrico $22,23,24,25,29,46$, os erros associados à inexatidão do ato de superposição ${ }^{2,22,23,25}$, os procedimentos de digitalização ${ }^{22,29}$ e as mudanças de crescimento nas áreas de regis$\operatorname{tro}^{4,16,22,23,24,25,29,30,32,34,37,46}$. No entanto, em se tratando da comparação de uma mesma pessoa em crescimento, estes fatores adversos poderiam ser minimizados pela obtenção padronizada das telerradiografias ${ }^{2,21,22,25,29,47}$, pela confecção precisa dos cefalogramas $2,12,21,22,29$ e por protocolos de superposições corretos ${ }^{2,22,31}$ sobre pontos cefalométricos ou estruturas anatômicas considerados relativamente estáveis ou menos influenciados pelo crescimento e desenvolvimento ${ }^{8,9,12,14,16,19,20,22,25,29,34,46,48}$ e de fá-

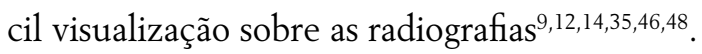

Para monitorar os procedimentos de tratamento, torna-se importante analisar os movimentos dos ossos maxilares por meio de superposições sobre estruturas anatômicas estáveis da base do crânio. Acredita-se que as melhores referências para superposições não se constituem em pontos cefalométricos, mas em áreas de registro naturais, ou os "melhores contornos anatômicos" da base craniana anterior e das estruturas palatinas e mandibulares ${ }^{2,19,28,30,35,48}$. Baseados nisto e na busca de alternativas que possibilitem superposições mais confiáveis, Björk, Skieller ; Houston, Lee ${ }^{22}$; Kerr ${ }^{25}$ e McWilliam $^{32}$ sugeriram a eliminação dos procedimentos do desenho anatômico, registrando-se os limites diretamente sobre as telerradiografias, por ser este método simples, rápido e não requerer materiais específicos. Contudo, a reprodutibilidade das superposições dos cefalogramas também é satisfatória, desde que estes sejam confeccionados com material apropriado e grande cuidado ${ }^{22}$.

As superposições cefalométricas constituem 


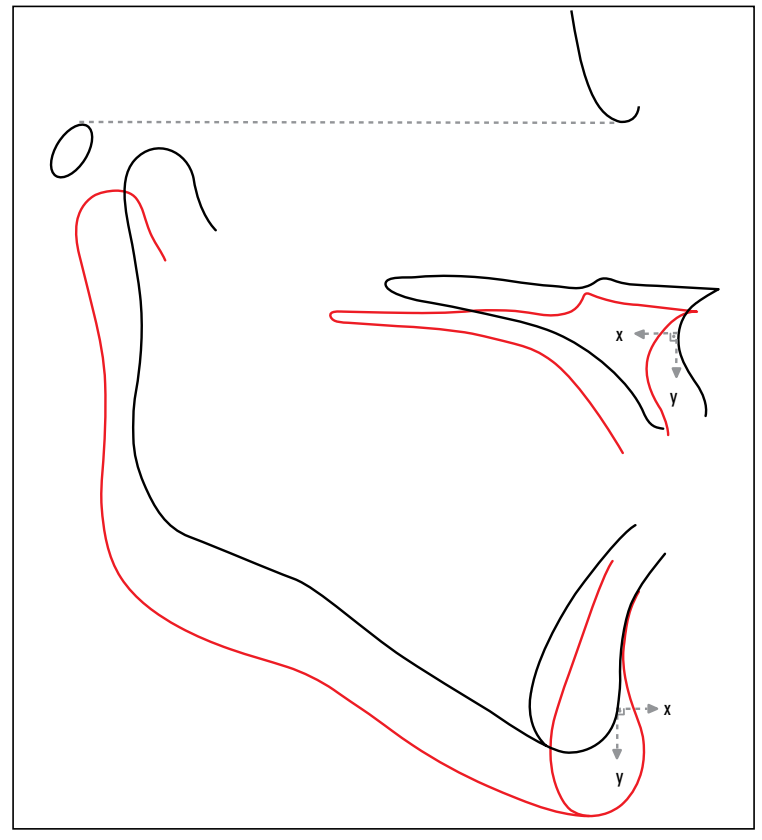

FIGURA 7 - Medidas lineares horizontais ( $\mathrm{x}$ ) e verticais (y) que traduzem a magnitude dos deslocamentos da maxila e da mandíbula.

um procedimento amplamente aceito e difundido na comunidade ortodôntica, indicando direções de crescimento e mudanças de tratamento com um grau de precisão satisfatório. No entanto, para Ghafari, Engel e Laster ${ }^{19}$, não se deve confiar excessivamente em apenas um método de superposição para se interpretarem os efeitos do crescimento e/ou tratamento. Afirmações semelhantes foram feitas por Lundström, Woodside ${ }^{28}$; McDowell ${ }^{31}$; Zampieri e Takahashi ${ }^{51}$, autores que aconselharam o emprego de mais de uma técnica de superposição cefalométrica com o intuito de se produzirem informações adicionais.

$\mathrm{Na}$ revisão de literatura, observou-se uma grande coincidência de opiniões no que se refere à utilização da base do crânio como área de registro para as superposições totais. Diversos autores concordam que, durante a época em que a maioria dos casos ortodônticos é tratada (9 a 14 anos), a base craniana é relativamente estável e considerada uma referência satisfatória na superposição dos cefalogramas seriados $8,9,12,13,14,18,19,20,35,50$, apesar de Björk $^{5}$ e McWilliam ${ }^{32}$ considerarem que esta es- trutura continua sendo submetida a modificações durante a adolescência. Além disso, na opinião de Björk $^{6}$, as superposições de telerradiografias sobre a base do crânio anterior são passíveis de erros, pois não se utilizam implantes nesta região. Verificou-se que a estabilidade e a precisão de alguns pontos ou áreas anatômicas são bastante discutidas. De acordo com os relatos de alguns pesquisadores $^{3,16,22,32,46}$, não existem pontos, linhas de referência ou limites anatômicos realmente fixos, os quais possibilitariam uma superposição precisa durante o crescimento e desenvolvimento e, segundo Fischer ${ }^{17}$, o problema inerente à superposição constitui-se em se localizar este ponto de referência destituído de mudanças de posição e forma ao longo de todos os estágios do crescimento. Não obstante, isto não constitui um problema sério para pequenos intervalos de observação ${ }^{22,28}$.

A superposição cefalométrica $\mathrm{TR}$, proposta por Broadbent ${ }^{9}$, que considerou estáveis o Plano Bolton-násio e o ponto de registro $\mathrm{R}$, produz resultados mais lógicos do que o método TSN, na opinião de Downs ${ }^{15}$, quando o ângulo da base do crânio násio-sela-básio aumenta com o crescimento, observando-se efeitos opostos nas situações em que este ângulo diminui. Já os participantes do "Second Research Workshop on Roentgenographic Cephalometrics" consideraram ser a superposição TR a mais confiável para estudos de crescimento e registros de mudanças dentofaciais sobre qualquer período considerável de tempo ${ }^{42}$. Todavia, Bambha ${ }^{1}$, De Coster $^{14}$ e Downs ${ }^{15}$ defrontaram-se com uma considerável dificuldade em se localizar com exatidão o ponto Bolton, por ele ser freqüentemente obscurecido pelo processo mastóide, fato também verificado nesta pesquisa no momento da demarcação deste ponto. Também deve ser considerado o relato de Moore $^{34}$ que alertou sobre a influência do crescimento na posição do ponto Bolton. O ponto cefalométrico násio, segundo Steiner ${ }^{44}$, é facilmente visualizado nas telerradiografias, apesar de Houston e Lee ${ }^{22}$ relatarem dificuldade para se localizar este ponto 
no plano vertical. A grande maioria dos autores pesquisados, por sua vez, assevera sobre a posição do ponto násio ser influenciada pelo crescimento, podendo este ponto ser deslocado para frente e para cima ou para baixo $1,4,6,7,14,18,19,22,24,28,33,34,43,48$.

Para determinar as alterações provenientes de crescimento e desenvolvimento ou de tratamento ortodôntico, a superposição total TSN constitui-se no método mais comumente utilizado por clínicos e pesquisadores ${ }^{22,24,33,48}$, tendo sido inicialmente indicada, segundo relato de Broadbent ${ }^{8}$, para as situações nas quais a distância entre os pontos sela e násio permanecia inalterada. De acordo com Vilella ${ }^{48}$, a utilização usual desta técnica decorre: da facilidade de seu emprego; de a linha sela-násio estar localizada no plano sagital mediano da cabeça; ser constituída por pontos facilmente identificáveis, em concordância com Ricketts ${ }^{41}$ e Steiner ${ }^{44}$; representar a base craniana anterior; e ser estável o suficiente durante o crescimento para assegurar sua validade como referência em superposições, sendo esta constatação endossada por Krogman ${ }^{26}$. Entretanto, diversos são os trabalhos na literatura que, em oposição a estes autores, alertam para a falta de estabilidade desta linha de referência, em função dos deslocamentos por crescimento dos pontos sela, para trás e para cima ou para baixo, e násio, para frente e para cima ou para baixo $^{1,4,6,7,14,18,19,22,24,28,33,34,43,48}$, além de o ponto násio não ser sempre facilmente localizado no plano vertical ${ }^{22}$. Apesar de o método TSN ser o mais convencional e amplamente aceito entre os ortodontistas, estes fatores adversos concorrem para a falta de confiabilidade técnica desta superposição, o que pode conduzir a uma impressão enganosa do padrão geral de crescimento da face, comprometendo a validade da linha sela-násio como referência em superposições ${ }^{4,22,24,36}$. Bambha ${ }^{1}$, Fischer $^{17}$ e Ford ${ }^{18}$ explicam que, em decorrência do deslocamento para cima do ponto násio, o método TSN demonstrará uma estimativa excessiva do crescimento vertical da face em comparação ao horizontal, o que corresponderia a uma falsa im- pressão de crescimento. Deste modo, Lundström e Woodside ${ }^{28}$ recomendam que esta técnica seja empregada em curtos intervalos de tempo, quando as mudanças de crescimento naturais na posição do násio forem mínimas.

As superposições cefalométricas estruturais sobre áreas de registro relativamente estáveis da base craniana anterior originaram-se em 1953, quando De Coster ${ }^{14}$ superpôs telerradiografias sobre uma linha compreendida pelo contorno anterior da sela túrcica, linha superior das massas esfenóides, sutura esfenoetmoidal, massas laterais e lâmina crivosa do etmóide, face encefálica das células frontais, forame cego e linha óssea interna do osso frontal até acima da crista frontal, parecendo ser esta referência inalterável após os 7 anos de idade e podendo ser utilizada confiavelmente em superposições. Em relação a esta referência, Richardson $^{39}$ comenta que a linha de De Coster é apenas moderadamente boa com respeito à reprodutibilidade, entretanto, torna-se mais bem reproduzida pela superposição direta das telerradiografias, possibilitando-se o registro de pequenos detalhes ósseos estruturais, com muito mais efetividade em comparação aos cefalogramas. Houston e $\mathrm{Lee}^{22}$, por sua vez, alertam que o contorno desta linha pode ser de difícil visualização e que muitos autores não a identificam corretamente, superpondo os tetos das órbitas que se remodelam e, além disso, comentam que existem mudanças de crescimento na base anterior do crânio, mesmo após a fusão da sincondrose esfenoetmoidal, com variações individuais consideráveis na quantidade e localização destas modificações. Ainda referindo-se à linha de De Coster, Vion ${ }^{49}$ observou um erro em seu enunciado, relatando seu desenho correto: borda anterior da sela túrcica, canal óptico, face superior do corpo do osso esfenóide, sutura esfenoetmoidal e porções horizontal e vertical da cortical interna do osso frontal. O erro consiste em tomar a porção horizontal da cortical interna do osso frontal pela lâmina crivosa do osso etmóide, que lhe é subjacente. Já outros pesquisadores sugeriram métodos 
de superposições cefalométricas totais estruturais sobre os "melhores contornos" anatômicos da base craniana anterior, não simplificando a anatomia desta região em linhas ou planos, em função dos resultados destas técnicas não serem influenciados pelas mudanças naturais de crescimento de pontos cefalométricos como, por exemplo, os pontos sela e násio, citando-se os trabalhos de Björk ${ }^{6}$; Björk, Skieller ${ }^{7}$; Ghafari, Engel, Laster ${ }^{19}$; Houston, Lee ${ }^{22}$; Lundström, Woodside ${ }^{28}$; Moorrees, Efstratiadis e Kent Junior ${ }^{35}$. No que tange a superposição TE, sua confiabilidade foi demonstrada por Buschang ${ }^{11}$, podendo-se superpor com exatidão os desenhos das estruturas de referência naturais, apesar da possível dificuldade de localização do ponto de intersecção médio entre os contornos inferiores dos processos clinóides anteriores com o contorno do tubérculo da sela, quando existem imagens duplas, acrescentando-se que a porção posterior da lâmina crivosa, anteriormente à fossa craniana média, mostrou-se especialmente estável e útil para superposições. De acordo com Vilella ${ }^{48}$, existe consenso no fato de que técnicas de superposições que se baseiam em contornos ósseos são mais confiáveis do que aquelas que tomam como referência apenas dois pontos, apesar de não serem rotineiramente utilizadas devido à dificuldade de sua execução.

Uma vez discutidos esses aspectos, passaremos a analisar os resultados referentes ao emprego das técnicas de superposições cefalométricas totais estrutural de Björk e Skieller (TE), sobre as linhas sela-násio, coincidindo-se os pontos sela (TSN) e sobre os pontos de registro $\mathrm{R}$, com os planos Bolton-násio paralelos (TR), imbuídos do propósito de verificar a existência de diferenças nos resultados apresentados por estes métodos.

Ao verificar a tabela 1 deste trabalho, percebe-se que todas as técnicas de superposições estudadas demonstraram um deslocamento da maxila em direção anterior, de modo mais acentuado para o método TSN, seguido do método TR e, em bem menor intensidade, pela técnica TE. Observandose as variáveis cefalométricas $\mathrm{A}-\mathrm{x}$ e $\mathrm{A}-\mathrm{y}$, que medem, respectivamente, a magnitude dos movimentos horizontais e verticais da maxila, constata-se que os deslocamentos verticais do ponto $\mathrm{A}$ excedem grandemente os horizontais para todas as técnicas de superposições. Em referência ao componente horizontal do movimento maxilar, apenas a técnica TE demonstrou diferenças estatisticamente significantes das demais, embora todas tenham apresentado um deslocamento para frente do ponto A, sendo que o deslocamento vertical da maxila ocorreu de modo estatisticamente semelhante ao horizontal, com movimento para baixo do ponto A em todos os métodos de superposições. Uma observação importante refere-se ao fato de que, nas situações em que se perceberam diferenças estatisticamente significantes entre os métodos de superposições em referência à magnitude dos movimentos horizontais e verticais da maxila, a técnica TE sempre denotou o menor deslocamento para frente e o maior para baixo da maxila, constituindo-se no método significantemente diferente dos demais. As superposições TSN e TR, por sua vez, não se mostraram estatisticamente diferentes no que diz respeito à magnitude dos movimentos horizontais e verticais maxilares.

Diante destes resultados e baseado na hipótese de que a técnica TE possa ser melhor do que as outras por considerar a anatomia individual detalhada da base do crânio, em concordância com os relatos de outros pesquisadores $7,11,14,19,25,28,32,35,48$, poder-se-ia afirmar que os métodos de superposições TSN e TR superestimam o deslocamento horizontal da maxila e subestimam o vertical, de maneira estatisticamente significante, observandose que a técnica TR demonstra esta característica, relativa ao movimento vertical, de forma mais evidente. Os resultados obtidos neste trabalho, referentes aos métodos TSN e TR, confirmam os de Bergersen ${ }^{4}$ que não encontrou diferenças significantes relativas aos deslocamentos faciais quando comparou as superposições TSN e TR. Por sua vez, Ghafari, Engel e Laster ${ }^{19}$ notaram diferenças estatisticamente significantes entre os métodos de 
superposições sobre o melhor contorno anatômico da base craniana anterior (similar à técnica TE), TSN e TR no que se refere aos pontos maxilares A, espinha nasal anterior e espinha nasal posterior. Faz-se necessário ressaltar que tanto a amostra quanto a metodologia por eles empregadas foram similares às utilizadas neste trabalho, visto que recorreram a telerradiografias pré e pós-tratamento de 26 pacientes entre as idades de 10 a 15 anos, sendo 13 do gênero masculino e 13 do feminino, inicialmente com más oclusões Classe II, divisão 1 tratados ortodonticamente com extrações dos quatro primeiros pré-molares. Além disso, basearam-se em um sistema coordenado estabelecido a partir de uma linha vertical, passando pelo ponto násio do cefalograma inicial (obtido com o paciente em posição natural da cabeça), sendo o eixo ( $\mathrm{x}$ ) perpendicular e o (y) paralelo a esta linha.

Com base no exame da tabela 1, verifica-se que em todos os métodos de superposições estudados a mandíbula se deslocou em direção anterior mas, em um menor grau, quando do emprego da técnica TE que se mostrou significantemente diferente das demais em relação à direção do deslocamento da mandíbula, ao passo que os métodos de superposições TSN e TR demonstraram intensidades similares do deslocamento anterior mandibular. De maneira similar ao comportamento da maxila, observa-se que a magnitude dos deslocamentos verticais mandibulares excedeu grandemente os horizontais em todos os métodos de superposições analisados, conforme indicam as variáveis cefalométricas Pog $-\mathrm{x}$ e Pog $-\mathrm{y}$, percebendo-se sempre um movimento para frente e para baixo do ponto pogônio. A análise da tabela 1 revela que a técnica TE demonstrou diferenças estatisticamente significantes em relação às superposições TSN e TR no que diz respeito tanto à magnitude do movimento horizontal quanto do vertical do ponto pogônio, sempre mostrando a menor magnitude de deslocamento horizontal e a maior de movimento vertical da mandíbula, percebendo-se que os métodos TSN e TR denotaram magnitudes equivalentes dos deslocamentos para frente e para baixo do pogônio, não havendo diferenciação estatística entre estas técnicas. Este efeito mostra que, também similarmente à maxila, as superposições TSN e TR superestimam o deslocamento horizontal mandibular e subestimam o vertical significantemente, quando comparadas ao método TE. Os resultados obtidos nesta pesquisa, relativos às técnicas TSN e TR, encontram-se em conformidade com os de Bergersen ${ }^{4}$ e Fischer ${ }^{17}$ que não denotaram diferenças estatisticamente significantes em relação aos movimentos faciais na comparação destes métodos de superposições. Ghafari, Engel e Laster ${ }^{19}$, por sua vez, observaram diferenças estatística e significantemente maiores que zero, relativas aos movimentos dos pontos $\mathrm{B}$, pogônio e gônio, entre as técnicas de superposições sobre o melhor contorno anatômico da base craniana anterior (similar ao método TE), TSN e TR.

Tabela 1 - Médias $(\bar{X})$ e desvios-padrão (DP) das medidas relativas aos deslocamentos faciais demonstrados pelas técnicas de superposições cefalométricas totais TE, TSN e TR, e os resultados estatísticos da análise de variância e do teste de Tukey (N=25).

\begin{tabular}{|c|c|c|c|c|c|c|c|c|c|}
\hline \multirow{2}{*}{ MEDIDAS } & \multicolumn{2}{|c|}{ TE } & \multicolumn{2}{|c|}{ TSN } & \multicolumn{2}{|c|}{ TR } & \multirow{2}{*}{$\mathbf{F}$} & \multirow{2}{*}{$\mathbf{p}$} & \multirow{2}{*}{ ns } \\
\hline & $\overline{\mathbf{X}}$ & DP & $\overline{\mathbf{x}}$ & DP & $\overline{\mathbf{X}}$ & DP & & & \\
\hline$\alpha m x$ & 1,26 & 26,03 & 12,04 & 31,66 & 10,76 & 29,54 & 2,416 & 0,100 & * \\
\hline$A-x$ & $0,28^{a}$ & 2,92 & $1,07^{\mathrm{b}}$ & 2,60 & $1,10^{\mathrm{b}}$ & 2,51 & 6,906 & 0,002 & * \\
\hline$A-y$ & $6,16^{\mathrm{a}}$ & 2,86 & $5,21^{\mathrm{b}}$ & 2,89 & $4,74^{\mathrm{b}}$ & 2,90 & 22,207 & 0,002 & * \\
\hline amd & $20,84^{\mathrm{a}}$ & 26,98 & $32,32^{b}$ & 25,63 & $33,46^{b}$ & 22,29 & 7,677 & 0,002 & * \\
\hline $\operatorname{Pog}-x$ & $3,67^{\mathrm{a}}$ & 5,08 & $5,05^{b}$ & 4,39 & $5,21^{b}$ & 4,34 & 6,849 & 0,002 & * \\
\hline Pog $-y$ & $8,84^{\mathrm{a}}$ & 4,14 & $7,95^{b}$ & 4,00 & $7,51^{b}$ & 3,79 & 18,191 & $<0,001$ & * \\
\hline
\end{tabular}

* diferença estatisticamente significante para $\mathrm{p}<0,05$; ns - não significante.

ab teste de Tukey: letras distintas indicam diferenças significantes entre as técnica. 
Contudo, considerando-se a hipótese de que somente uma diferença maior que 1 milímetro seja clinicamente significante, não encontraram diferenças clínica e estatisticamente significantes para qualquer limite mandibular entre todos os métodos, indicando que eles produziriam informações similares acerca do movimento mandibular.

Cabe ressaltar que os resultados aqui considerados basearam-se no comportamento médio de cada variável cefalométrica da amostra estudada. Neste contexto, não podemos excluir a ocasional ocorrência de diferentes interpretações na análise de um modelo individual de crescimento e desenvolvimento associado a tratamento ortodôntico, sendo que não se visou estabelecer a superioridade de um método de superposição cefalométrica total em detrimento de outros. Existe a expectativa de que, ao se perceber a grande utilidade das informações oriundas das técnicas de superposições cefalométricas, possam ser desenvolvidas pesquisas bem elaboradas em trabalhos futuros.

\section{CONCLUSÕES}

De acordo com a metodologia utilizada e com base nos resultados obtidos neste trabalho, julgouse lícito concluir que:

- Os métodos de superposições demonstraram resultados diferentes em relação à direção e magnitude dos deslocamentos da maxila e da mandíbula.

- O método TE (Sobreposição estrutural de Björk, Skieller) demonstrou deslocamentos significantemente menores para frente e maiores para baixo da maxila e da mandíbula.

- Os métodos TSN (Sobreposição Sela-Násio) e TR (Sobreposição em R, com Bolton-Násio paralelos) não se mostraram estatisticamente diferentes quanto à direção e magnitude dos deslocamentos da maxila e da mandíbula.

\title{
Comparative study among total cephalometric superimposition techniques
}

\begin{abstract}
Aim: this study was aimed at verifying whether there are differences among the results obtained by total superimposition techniques. Methods: a sample of 50 cephalometric X-rays from patients aged 8.25-16.25 years was used to assess the alterations that derive from craniofacial growth and development, as well as from orthodontic treatment. Cephalometric variables representative of direction and magnitude of displacements of facial-skeletal components were used to assess those alterations. Results and Conclusion: we concluded that superimposition techniques can produce significantly different results.
\end{abstract}

Key words: Cephalometric superimposition. Roentgenographic cephalometrics. Serial films.

\section{REFERÊNCIAS}

1. BAMBHA, J. K. Longitudinal cephalometric roentgenographic study of face and cranium in relation to body height. J Am Dent Ass, Chicago, v. 63, no. 6, p. 776-799, Dec. 1961.

2. BAUMRIND, S.; MILLER, D.; MOLTHEN, R. The reliability of head film measurements. 3. Tracing superimposition. Am J Orthod, St. Louis, v. 70, no. 6, p. 617-644, Dec. 1976.
Enviado em: Maio de 2003 Revisado e aceito: Junho de 2003 
6. BJÖRK, A. The use of metallic implants in the study of facial growth in children: method and application. Am J Phys Anthrop, Philadelphia, v. 29, no. 2, p. 243-254, Sept. 1968.

7. BJÖRK, A.; SKIELLER, V. Normal and abnormal growth of the mandible. A synthesis of longitudinal cephalometric implant studies over a period of 25 years. Eur J Orthod, Oxford, v. 5, no. 1, p. 1-46, Feb. 1983

8. BROADBENT, B. H. A new x-ray technique and its application to Orthodontia. Angle Orthod, Appleton, v. 1, no. 2, p. 45-66, Apr. 1931

9. BROADBENT, B. H. The face of the normal child. Angle Orthod, Appleton, 7, no. 4, p. 183-208, Oct. 1937.

10. BRODIE, A. G. On the growth pattern of the human head. From the third month to the eighth year of life. Am J Anat, New York, v. 68 , no. 2, p. 209-262, Mar. 1941

11. BUSCHANG, P. H. The technical reliability of superimposition on cranial base and mandibular structures. Eur J Orthod, Oxford, v. 8 , no. 3 , p. $152-156$, Aug. 1986

12. CAUFIELD, P. W. Tracing technique and identification of landmarks. In: JACOBSON, A. Radiographic cephalometry: from basics to videoimaging. Chicago: Quintessence, 1995. cap. 4, p. 53-63.

13. COBEN, S. E. Growth and Class II treatment. Am J Orthod, St. Louis, v. 52, no. 1, p. 5-26, Jan. 1966

14. DE COSTER, L. A new line of reference for the study of lateral facial teleradiographs. Am J Orthod, St. Louis, v. 39, no. 4, p. 304-306, Apr. 1953.

15. DOWNS, W. B. Analysis of the dentofacial profile. Angle Orthod, Appleton, v. 26, no. 4, p. 191-212, Oct. 1956.

16. ENLOW, D. H. A morphogenetic analysis of facial growth. Am J Orthod, St. Louis, v. 52, no. 4, p. 283-299, Apr. 1966.

17. FISCHER, T. J. The cervical facebow and mandibular rotation. Angle Orthod, Appleton, v. 50, no. 1, p. 54-62, Jan. 1980.

18. FORD, E. H. R. Growth of the human cranial base. Am J Orthod, St. Louis, v. 44, no. 7, p. 498-506, July 1958

19. GHAFARI, J.; ENGEL, F. E.; LASTER, L. L. Cephalometric superimposition on the cranial base: A review and a comparison of four methods. Am J Orthod Dentofacial Orthop, St. Louis, v. 91 , no. 5 , p. 403-413, May 1987.

20. HIGLEY, L. B. Lateral head roentgenograms and their relation to the orthodontic problem. Am J Orthod Oral Surg, St. Louis, v. 26 , no. 8 , p. $768-778$, Aug. 1940

21. HOUSTON, W. J. B. The analysis of errors in orthodontic measurements. Am J Orthod, St. Louis, v. 83, no. 5, p. 382-390, May 1983.

22. HOUSTON, W. J. B.; LEE, R. T. Accuracy of different methods of radiographic superimposition on cranial base structures. Eur $\mathbf{J}$ Orthod, Oxford, v. 7, no. 2, p. 127-135, May 1985.

23. JACOBSON, A. How reliable is cephalometric prediction? In: . Radiographic cephalometry: from basics to videoimaging. Chicago: Quintessence, 1995. cap. 22, p. 295-303.

24. JACOBSON, A.; SADOWSKY, P. L. Superimposition of cephalometric radiographs. In: JACOBSON, A. Radiographic cephalometry: from basics to videoimaging. Chicago: Quintessence, 1995. cap. 12, p. 165-173.

25. KERR, W. J. S. A method of superimposing serial lateral cephalometric films for the purpose of comparison: a preliminary report. Br J Orthod, Oxford, v. 5, no. 1, p. 51-53, Jan. 1978.

26. KROGMAN, W. M. Craniometry and cephalometry as research tools in growth of head and face. Am J Orthod, St. Louis, v. 37, no. 6, p. 406-414, June 1951.

27. LANDE, M. J. Growth behavior of the human bony facial profile as revealed by serial cephalometric roentgenology. Angle Orthod, Appleton, v. 22, no. 2, p. 78-90, Apr. 1952.

28. LUNDSTRÖM, A.; WOODSIDE, D. G. Individual variation in growth directions expressed at the chin and the midface. Eur $\mathbf{J}$ Orthod, Oxford, v. 2, no. 2, p. 65-79, 1980.

29. MACRI, V.; ATHANASIOU, A. E. Sources of error in lateral cephalometry. In: ATHANASIOU, A. E. Orthodontic cephalometry. London: Mosby-Wolfe, 1995. cap. 5, p. 125-140.

30. MATHEWS, J. R.; PAYNE, G. S. Quantitative computerized analysis of lower incisor changes: a longitudinal implant study in man. Angle Orthod, Appleton, v. 50, no. 3, p. 218-229, July 1980.
31. McDOWELL, R. M. The use of lateral head radiographs for evaluating orthodontic results as distinguished from growth changes. Part I. Technique and statement of problem. Am J Orthod Oral Surg, St. Louis, v. 27, no. 2, p. 59-74, Feb. 1941.

32. MCWILLIAM, J. S. The effect of growth on the precision of subtraction superimposition. Dentomaxillofac Radiol, Houndsmills, v. 12 , no. 1, p. 61-69, 1983

33. MEROW, W. W.; BROADBENT JUNIOR, B. H. Cefalometria. In: ENLOW, D. H. Crescimento facial. 3. ed. São Paulo: Artes Médicas, 1993. cap. 14, p. 334-381.

34. MOORE, A. W. Observations on facial growth and its clinical significance. Am J Orthod, St. Louis, v. 45, no. 6, p. 399-423, June 1959.

35. MOORREES, C. F. A.; EFSTRATIADIS, S. S.; KENT JUNIOR, R L. The complexity of facial growth analysis. In: JACOBSON A. Radiographic cephalometry: from basics to videoimaging. Chicago: Quintessence, 1995. cap. 11, p. 137-163.

36. PANCHERZ, $\mathrm{H}_{\text {; }}$ HANSEN, $\mathrm{K}$. The nasion-sella reference line in cephalometry: a methodologic study. Am J Orthod, St. Louis, v. 86 , no. 5 , p. 427-434, Nov. 1984

37. PEREIRA, C. B.: MUNDSTOCK, C. A.; BERTHOLD, T. B. Introdução à cefalometria radiográfica. 3. ed. São Paulo: Pancast, 1998.

38. PROFFIT, W. R.; FIELDS JUNIOR, H. W. Diagnóstico ortodôntico: o desenvolvimento de uma lista de problemas. In: Ortodontia contemporânea. 2. ed. Rio de Janeiro: Guanabara Koogan, 1995. cap. 6, p. 127-169.

39. RICHARDSON, A. An investigation into the reproducibility of some points, planes, and lines used in cephalometric analysis Am J Orthod, St. Louis, v. 52, no. 9, p. 637-651, Sept. 1966.

40. RICKETTS, R. M. A four-step method to distinguish orthodontic changes from natural growth. J Clin Orthod, Boulder, v. 9, no. 4, p. 208-215, 218-228, Apr. 1975.

41. RICKETTS, R. M. Perspectives in the clinical application of cephalometrics. The first fifty years. Angle Orthod, Appleton v. 51, no. 2, p. 115-150, Apr. 1981

42. SALZMANN, J. A. The research workshop on cephalometrics. Am J Orthod, St. Louis, v. 46, no. 11, p. 834-847, Nov. 1960

43. SCOTT, J. H. Growth at facial sutures. Am J Orthod, St. Louis, v. 42, no. 5, p. 381-387, May 1956.

44. STEINER, C. C. Cephalometrics for you and me. Am J Orthod St. Louis, v. 39, no. 10, p. 729-755, Oct. 1953.

45. STEINER, C. C. Cephalometrics in clinical practice. Angle Orthod, Appleton, v. 29, no. 1, p. 8-29, Jan. 1959.

46. STEUER, I. The cranial base for superimposition of lateral cephalometric radiographs. Am J Orthod, St. Louis, v. 61, no. 5, p. 493-500, May 1972.

47. THUROW, R. C. Cephalometric methods in research and private practice. Angle Orthod, Appleton, v. 21, no. 2, p. 104-116, Apr. 1951.

48. VILELLA, O. V. Superposição de traçados. In:__. Manual de cefalometria. 2. ed. Rio de Janeiro: Guanabara Koogan, 2001. cap. 6, p. 123-135

49. VION, P. E. Anatomia telerradiográfica em norma lateralis. In: Anatomia cefalométrica. São Paulo: Ed. Santos, 1994. p. 3-91.

50. WIESLANDER, L. The effect of orthodontic treatment on the concurrent development of the craniofacial complex. Am J Orthod, St. Louis, v. 49, no. 1, p. 15-27, Jan. 1963.

\section{Endereço para correspondência}

Ricardo Fernando Zampieri

Espírito Santo no 1163 - sala 503 - Centro

CEP: 86020-420 - Londrina/PR

E-mail: ricardofz@sercomtel.com.br 